\title{
Faith Cures, Doctor Treats: Management of a Case of Pancreatic Trauma in a Jehovah's Witness Patient
}

\author{
Galvin Dhaliwal ${ }^{1}$ Pranay Pawar ${ }^{2}$ Renji Matthew ${ }^{1} \quad$ Navneet Kumar Chaudhry ${ }^{1}$ \\ ${ }^{1}$ Department of General Surgery, Christian Medical College and \\ Hospital Ludhiana, Ludhiana, Punjab, India \\ 2Division of Vascular Surgery, Department of General Surgery, \\ Christian Medical College and Hospital Ludhiana, Ludhiana, \\ Punjab, India

\begin{abstract}
Address for correspondence Pranay Pawar, MBBS, MD, MCh, Division of Vascular Surgery, Department of General Surgery, Christian Medical College and Hospital Ludhiana, Brown Road, CMC Campus, Ludhiana 141008, Punjab, India (e-mail: pranay584@yahoo.co.in).
\end{abstract}

Int J Recent Surg Med Sci 2019;5:62-63

\begin{abstract}
Keywords

- Jehovah's Witness

- pancreatic trauma

- distal pancreatectomy

- road traffic accident

The awareness about Jehovah's Witness in India is very poor. One of the fundamentals of their beliefs is prohibition of blood and blood product transfusions. This presents a unique challenge, especially when coupled with massive trauma. We describe a rare case of a patient presenting with massive abdominal trauma who was managed successfully.
\end{abstract}

\section{Introduction}

The Jehovah's Witness religion is a Christian movement with 6.3 million followers worldwide. This community does not accept blood or blood products based on their belief. When compounded with a trauma scenario in India, where there is a lack of awareness about this community, this leads to creation of obstacles in their treatment plan along with legal, medical, and ethical challenges for the health care provider. ${ }^{1}$

\section{Case Report}

A 42-year-old male, belonging to Jehovah's Witness sect, presented to casualty with history of having sustained a handlebar injury to the epigastrium while driving a motorcycle approximately 4 hours before presentation. He was hemodynamically stable and maintaining saturation. Per abdomen examination revealed generalized tenderness with guarding. The hemoglobin was $6.8 \mathrm{~g} \%$, while the rest of laboratory parameters were normal. A contrast computed tomography (CT) scan was performed which revealed a grade-I liver injury, grade-II splenic injury, suspected bowel perforation at first part of duodenum, and grade-III pancreatic injury (-Figs. 1 and 2). The patient was taken for an exploratory laparotomy. The relatives as well as the patient did not consent to the use of blood products.

On exploration the following findings were noted:

1. Transection of pancreas at level of the neck sparing the ampulla

2. Total transection of first part of duodenum proximal to ampulla

3. Grade-1 liver laceration at segment VII

4. Grade-III splenic laceration

5. Approximately $1,000 \mathrm{~mL}$ of hemoperitoneum

The distal end of the transected duodenum was closed with $2-0$ silk and a distal gastrectomy was done. The proximal part of the pancreatic duct was identified and closed with 3-0 prolene and the distal transected pancreas was removed. A retrocolic Roux-en-Y gastrojejunostomy, splenectomy, cholecystectomy, and feeding jejunostomy were performed.

Postoperatively, the patient remained stable with hemoglobin of $6.2 \mathrm{~g} \%$. He was started on injection erythropoietin 10,000 unit once daily and parental iron. He was started on jejunostomy feeds on day 3 . He was discharged after 14 days in a stable condition on pancreatic enzyme supplements. On discharge his hemoglobin was $10.9 \mathrm{~g} \%$. On regular follow-up, he was healthy and free of any postoperative complications. 


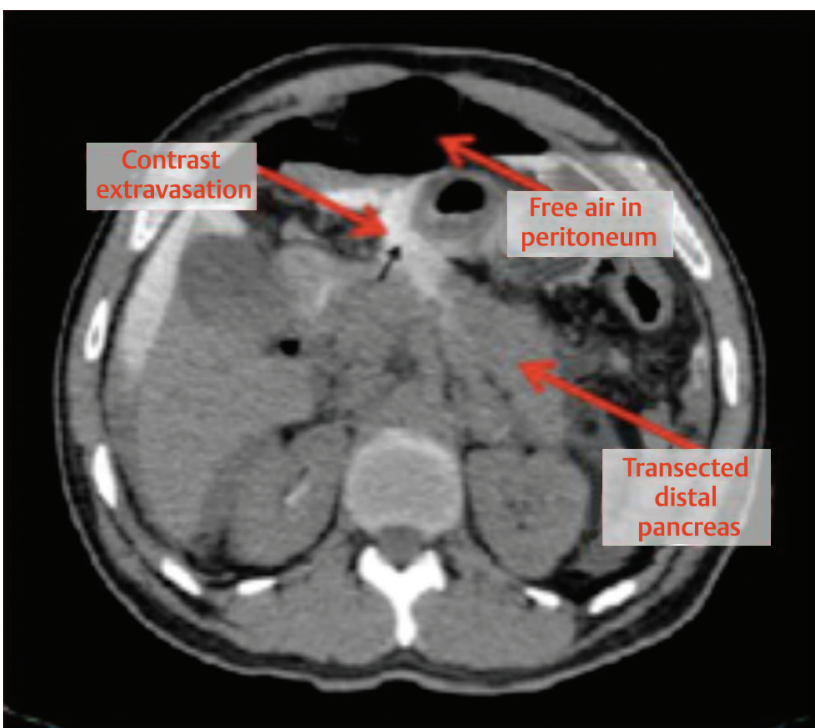

Fig. 1 CT scan showing extravasation of contrast in case of traumatic injury to pancreas. $\mathrm{CT}$, computed tomography.

\section{Discussion}

Pancreatic trauma occurs in $4 \%$ of all patients with abdominal trauma. Due to its intimate relationship with major upper abdominal vessels and viscera, it is associated with significant morbidity and mortality., ${ }^{2,3}$ A high degree of suspicion is required to diagnose a case of pancreatic trauma. A CT scan is the best noninvasive modality to diagnose pancreatic injury with sensitivity and specificity of $80 \%$ and is graded according to the American Association for the Surgery of Trauma grading. Grades I and II injuries are usually managed with local debridement and closed drainage. Grade III requires a distal pancreatectomy and splenectomy, and grades IV and V need a pancreaticoduodnectomy. The most important prognostic factor is the presence of ductal injury and early diagnosis and management of it. ${ }^{4}$

The Jehovah's Witness religion is a Christian movement, which was founded in 1872 by Charles Russell. The refusal of blood products is core value of their faith and the members would regard transfusion without consent as a gross physical violation. This proves challenging for surgeons and anesthetists in elective and, especially, emergency cases. ${ }^{5}$

In elective surgeries, the patient can be referred to a center that has dealt with similar cases where preoperative optimization with iron and vitamin B12 supplementation, erythropoietin therapy, use of hypotensive anesthesia, acute hypervolemic hemodilution, and technology like harmonic scalpel and intraoperative cell salvage therapy (cell saver) can be used. ${ }^{6}$

However, the scenario in emergency cases is markedly different. All the emphasis is on intraoperative control and recovery of blood. Some of the techniques in use are as follows:

1. Use of hemostatic devices such as harmonic scalpel and topical agents such as fibrin glue, bone wax, or thrombin gel.

2. Hypotensive anesthesia, regional anesthesia, and acute hypervolemic hemodilution are helpful in reducing blood loss.

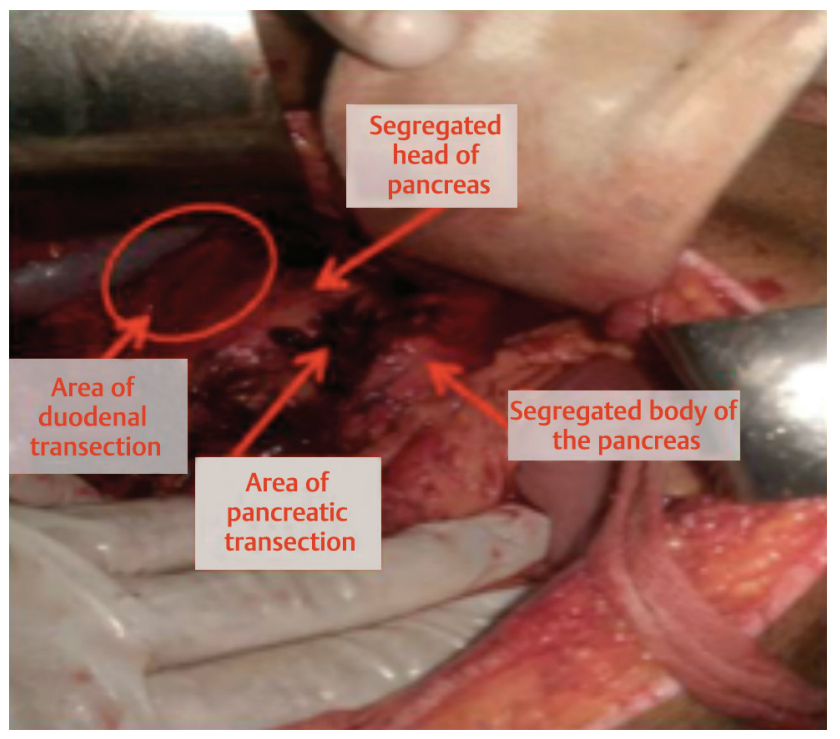

Fig. 2 Intraoperative picture showing transected pancreas and duodenum.

3. Use of intra- and postoperative cell salvage devices

4. Controlled hypothermia to reduce oxygen consumption

5. Pharmacologic agents such as antifibrinolytics and recombinant activated factor VII

6. Red blood cell substitutes (HbOC's) can also be used, but are still in phase-III clinical trials ${ }^{6,7}$

\section{Conclusion}

Even with the strictures that the religious beliefs of Jehovah's Witnesses place on surgeons, successful management is possible without blood products even in patients with life-threatening trauma.

\section{Conflict of Interest}

None declared.

\section{References}

1 Nishant KR, Kumari R. Surgical management in treatment of Jehovah's witness in trauma surgery in Indian subcontinent. J Emerg Trauma Shock 2014;7(3):215-221

2 Lahiri R, Bhattacharya S. Pancreatic trauma. Ann R Coll Surg Engl 2013;95(4):241-245

3 Boffard KD, Brooks AJ. Pancreatic trauma-injuries to the pancreas and pancreatic duct. Eur J Surg 2000;166(1):4-12

4 Bradley EL, III, Young PR, Jr., Chang MC, et al. Diagnosis and initial management of blunt pancreatic trauma: guidelines from a multiinstitutional review. Ann Surg 1998;227(6):861-869

5 Trzciński R, Kujawski R, Mik M, Berut M, Dziki Ł, Dziki A. Surgery in Jehovah's Witnesses - our experience. Prz Gastroenterol 2015;10(1):33-40

6 Chand NK, Subramanya HB, Rao GV. Management of patients who refuse blood transfusion. Indian J Anaesth 2014;58(5):658-664

7 Chen J-Y, Scerbo M, Kramer G. A review of blood substitutes: examining the history, clinical trial results, and ethics of hemoglobin-based oxygen carriers. Clinics (São Paulo) 2009;64(8):803-813 